\title{
Secondhand smoke exposure and risk following the Irish smoking ban: an assessment of salivary cotinine concentrations in hotel workers and air nicotine levels in bars
}

\author{
M Mulcahy, D S Evans, S K Hammond, J L Repace, M Byrne
}

Tobacco Control 2005;14:384-388. doi: 10.1136/tc.2005.011635

See end of article for authors' affiliations

Correspondence to: Maurice Mulcahy, MSc, Principal Environmental Health Officer, Health Service Executive, Western Area, The Annex, Seamus Quirke Road, Galway, Republic of Ireland; mauricemulcahy@eircom. net

Received 23February 2005 Accepted 28 September 2005

\begin{abstract}
Objective: To investigate whether the Irish smoking ban has had an impact on secondhand smoke (SHS) exposures for hospitality workers.

Design, setting, and participants: Before and after the smoking ban a cohort of workers $(n=35)$ from a sample of city hotels $(n=15)$ were tested for saliva cotinine concentrations and completed questionnaires. Additionally, a random sample $(n=20)$ of city centre bars stratified by size (range 400-5000 square feet), were tested for air nicotine concentrations using passive samplers before and after the ban.

Main outcome measures: Salivary cotinine concentrations $(\mathrm{ng} / \mathrm{ml})$, duration of self reported exposures to secondhand smoke, air nicotine ( $\mu \mathrm{g} /$ cubic metre).

Results: Cotinine concentrations reduced by $69 \%$, from $1.6 \mathrm{ng} / \mathrm{ml}$ to $0.5 \mathrm{ng} / \mathrm{ml}$ median (SD 1.29 ; $p<0.005$ ). Overall 74\% of subjects experienced decreases (range 16-99\%), with $60 \%$ showing a halving of exposure levels at follow up. Self reported exposure to SHS at work showed a significant reduction from a median 30 hours a week to zero $(p<0.001)$. There was an $83 \%$ reduction in air nicotine concentrations from median $35.5 \mu \mathrm{g} / \mathrm{m}^{3}$ to $5.95 \mu \mathrm{g} / \mathrm{m}^{3}(\mathrm{p}<0.001)$. At baseline, three bars $(16 \%)$ were below the $6.8 \mu \mathrm{g} / \mathrm{m}^{3}$ air nicotine significant risk level for lung cancer alone; at follow up this increased to 10 (53\%).

Conclusions: Passive smoking and associated risks were significantly reduced but not totally eliminated. Exposure to SHS is still possible for those working where smoking is still allowed and those working where smoke may migrate from outdoor areas. Further research is required to assess the true extent and magnitude of these exposures.
\end{abstract}

O n the 29 March 2004, Ireland became the first country to introduce a smoking ban in indoor workplaces. Smoking has been banned in all bars, restaurants, cafes, and hotels (excluding bedrooms, outdoor areas, and properly designed smoking shelters). ${ }^{1}$ The ban aims to protect workers, particularly those in the hospitality industry, from the health consequences of secondhand smoking (SHS) such as increased risks for lung cancer, coronary heart disease, and asthma. ${ }^{2-5}$

Although several studies have assessed exposure levels relative to workplace smoking policy, ${ }^{6-9}$ relatively few studies have illustrated the levels of exposure of those most highly exposed such as hospitality workers ${ }^{6-15}$ and fewer still have assessed the exposure reductions yielded by smoking bans. ${ }^{16-18}$ As more jurisdictions consider legislating for smoke-free workplaces, these may become the most sought after elements of the evidence base. The purpose of this research was to investigate whether the Irish smoking ban has had an impact on SHS exposures for hotel and bar workers.

\section{METHODS}

\section{Cotinine monitoring of hotel workers}

Cotinine is a biomarker of recent passive smoking exposure, as it is produced when the body breaks down nicotine absorbed over the previous 2-3 days. ${ }^{19}$ Saliva samples were obtained from a sample of hospitality staff $2-3$ weeks before (baseline) and 4-6 weeks after (follow up) the smoking ban. All 40 hotels in Galway city in the Health Service Executives'
Environmental Health database were visited. Each manager was asked for permission to approach staff and request their participation in the study. Hotel staff were then recruited; screening questions ensured participants were non-smokers from non-smoking or restricted smoking households (less than 45 minutes exposure per day to one smoker). All participants gave informed consent. The saliva samples were obtained during a working shift using salivettes (Sarstedt Ltd, County Waterford, Ireland; part no. 15/1534) and the time worked before the test recorded. The samples were coded and stored in cool boxes before frozen storage within three hours. Samples were shipped in dry ice to ABS Laboratories, London for analysis by gas chromatography. ${ }^{20}$ Baseline demographic data were obtained with a questionnaire completed after the cotinine test.

\section{Airborne nicotine monitoring of bars}

Passive samplers were located behind the bar counters of 20 city centre bars for 7-10 hours, on the Friday preceding the ban (baseline) and six weeks later (follow up). An even number of bars were selected randomly from a database categorised into small, medium, large, and super pubs. Of the 20 bars approached, none refused to participate. Four follow up samples had to be repeated because of lost data. As one venue had closed, 19 of the 20 venues were sampled at follow

Abbreviations: $C H D$, coronary heart disease; LDL-C, low density lipoprotein cholesterol; OHSA, US Occupational Safety and Health Administration; SHS, secondhand smoke 
up. The passive samplers contained a filter treated with sodium bisulphate and are known to be sensitive and accurate measures of vapour phase nicotine. ${ }^{21}$ All samplers were clipped to spirit drink dispensers in the bars before lunchtime on Fridays and collected during the evening. In order to be able to interpret whether recorded levels were associated with high/low smoking rates, and to check for tampering with the samplers between times, a series of observations were made. At the time of placing and retrieving the samplers, the number of occupants and smokers in the bar was recorded. In addition, two further counts were covertly undertaken, also checking the positioning of the sampler for signs of tampering. Samples were sent to the Chemist Service Laboratory, Public Health Agency, Barcelona, Spain, for analysis by gas chromatography/mass spectrometry. Weather conditions at both baseline and follow up were mild/fine with no rain.

\section{RESULTS}

Profile

At baseline 52 workers from 15 hotels gave saliva samples and completed a questionnaire. Eight workers (15\%) refused to participate in the study. At follow up, 11 participating workers were unavailable to give samples as they no longer worked at the venues and so they were excluded (baseline cotinine values: $0.2,0.5,1.3,2.2,3.9,4.1,5.6,10.5,14.1,31.4$, and $105.1 \mathrm{ng} / \mathrm{ml}$ ). In addition, to control for misreported smoking status, we excluded subjects with saliva concentrations exceeding $15 \mathrm{ng} / \mathrm{ml}^{20} 22$ (baseline cotinine values: 21.8 , $64.9,107.9,161.3,322.9$, and $349.7 \mathrm{ng} / \mathrm{ml}$, respectively). Baseline and follow up comparisons were therefore undertaken on 35 of the 55 workers at 15 of the hospitality venues. The baseline profile of subjects is given in table 1 .

Bar venues ranged in size from 384 square feet to 5200 square feet and represented a cross section of venue types including traditional bars, music bars, hotel bars, and super pubs. At follow up eight bars had provided newly designated outdoor smoking areas. These uncovered areas were adjacent to main entrance doorways and consisted of areas cordoned off by waist level demountable screens.

\section{Cotinine concentration}

At baseline, $20 \%$ of workers had cotinine concentrations above $5 \mathrm{ng} / \mathrm{ml}$, with $6 \%$ having concentrations greater than $10 \mathrm{ng} / \mathrm{ml}$. At follow up, no cotinine concentrations greater than $5 \mathrm{ng} / \mathrm{ml}$ were recorded (fig 1). At baseline $80 \%$ exceeded $0.57 \mathrm{ng} / \mathrm{ml}$ with this reducing to $49 \%$ at follow up. Overall $74 \%$ experienced decreases of $16-99 \%$, with over a third of all hotel staff (34\%) experiencing reductions greater than $70 \%$. For $60 \%$, exposure levels were halved at follow up. Of the nine that experienced increases, all were less than $2 \mathrm{ng} / \mathrm{ml}$. Workers were tested 6.6 hours into their shift on average at baseline and 4.95 hours into their shift at follow up.

Table 2 shows that median cotinine concentrations declined from $1.6 \mathrm{ng} / \mathrm{ml}$ at baseline to $0.5 \mathrm{ng} / \mathrm{ml}$ at follow up $(\mathrm{p}<0.005: 95 \%$ confidence interval $(\mathrm{CI}))$. This represents a $69 \%$ reduction in median cotinine concentrations. Median concentrations reduced for all types of work except management, which experienced a small, insignificant increase from already low values $(\mathrm{p}>0.05)$. Reductions were significant for waiters and "other" duties ( $\mathrm{p}<0.05$ : 95\% CI) undertaken by $31 \%$ of workers-namely, front desk (3), portering (2), leisure club (1), accommodation (2), and kitchen (1) bar staff (2) $(\mathrm{p}<0.05: 95 \% \mathrm{CI})$. The highest median cotinine concentrations at baseline and at follow up were experienced by bar staff (5.4 and $2.6 \mathrm{ng} / \mathrm{ml}$ ) and waiters (3.9 and $1.6 \mathrm{ng} / \mathrm{ml}$ ).

A reduction in median cotinine concentrations from 1.6 to $1.4 \mathrm{ng} / \mathrm{ml}(\mathrm{p}<0.05)$ was experienced by subjects living in households where no one smoked $(n=23)$. Those living in restricted smoking households $(n=12)$ experienced a reduction in median cotinine concentrations from $1.45 \mathrm{ng} / \mathrm{ml}$ to $0.4 \mathrm{ng} / \mathrm{ml}(\mathrm{p}<0.05)$.

Self reported exposure to SHS at work showed a significant reduction from a median of 30 hours a week at baseline, to a median of zero at follow up ( $\mathrm{p}<0.001$ : $95 \% \mathrm{CI})$. At baseline, $68 \%$ reported that they had over 21 hours of exposure to SHS with $23 \%$ having up to 20 hours of exposure and $10 \%$ having no exposure. At follow up, $70 \%$ reported no exposure and $30 \%$ reported 1-2 hours of exposure at work in the last seven days.

\section{Air nicotine}

The median air nicotine concentrations reduced significantly from $35.52 \mu \mathrm{g} / \mathrm{m}^{3} \quad\left(\right.$ mean $\left.=35.81 \mu \mathrm{g} / \mathrm{m}^{3} \quad \mathrm{SD}=25.74\right) \quad$ to $5.95 \mu \mathrm{g} / \mathrm{m}^{3}\left(\right.$ mean $\left.=10.23 \mu \mathrm{g} / \mathrm{m}^{3} \mathrm{SD}=9.66\right)$ representing an 83\% reduction in air nicotine levels ( $p<0.01$ : 95\% CI). Reductions were experienced in 16 of the 19 bars at follow up (fig 2). The level of reduction ranged from 38-90\%. At baseline higher concentrations were generally observed in medium and small sized bars than in large bars and super pubs. Only small and medium venues exceeded $60 \mu \mathrm{g} / \mathrm{m}^{3}$ at baseline and only small bars exceeded $20 \mu \mathrm{g} / \mathrm{m}^{3}$ at follow up. The three venues that experienced increases in air nicotine concentrations had low concentrations at baseline $(<6 \mu \mathrm{g} /$ $\left.\mathrm{m}^{3}\right)$ and at follow up remained below the average $(<10 \mu \mathrm{g} /$ $\mathrm{m}^{3}$ ) At baseline, three bars (16\%) were below $6.8 \mu \mathrm{g} / \mathrm{m}^{3}$, at

\begin{tabular}{|c|c|c|c|c|c|c|}
\hline & \multicolumn{2}{|c|}{ Male } & \multicolumn{2}{|c|}{ Female } & \multicolumn{2}{|c|}{ Total } \\
\hline & $\mathrm{n}$ & $\%$ & n & $\%$ & $n$ & $\%$ \\
\hline \multicolumn{7}{|l|}{ Age } \\
\hline $18-21$ & 2 & 13 & 10 & 53 & 2 & 6 \\
\hline $22-30$ & 5 & 31 & 8 & 42 & 15 & 43 \\
\hline $31-40$ & 7 & 38 & 1 & 5 & 14 & 40 \\
\hline $41-50$ & 3 & 19 & & & 4 & 11 \\
\hline People allowed to smoke in home & 11 & 69 & 7 & 37 & 18 & 51 \\
\hline \multicolumn{7}{|l|}{ Length of time current job } \\
\hline$<6$ months & 5 & 31 & 0 & 0 & 5 & 15 \\
\hline 6 months to 1 year & 1 & 6 & 9 & 50 & 10 & 30 \\
\hline $1-3$ years & 5 & 31 & 3 & 17 & 8 & 24 \\
\hline $3+$ years & 5 & 31 & 6 & 33 & 11 & 32 \\
\hline \multicolumn{7}{|l|}{ Work duties } \\
\hline Waiting & 4 & 25 & 7 & 37 & 11 & 31 \\
\hline Management & 5 & 31 & 5 & 26 & 10 & 29 \\
\hline Other & 5 & 31 & 6 & 32 & 11 & 32 \\
\hline Mixture & 2 & 13 & 1 & 5 & 3 & 9 \\
\hline
\end{tabular}




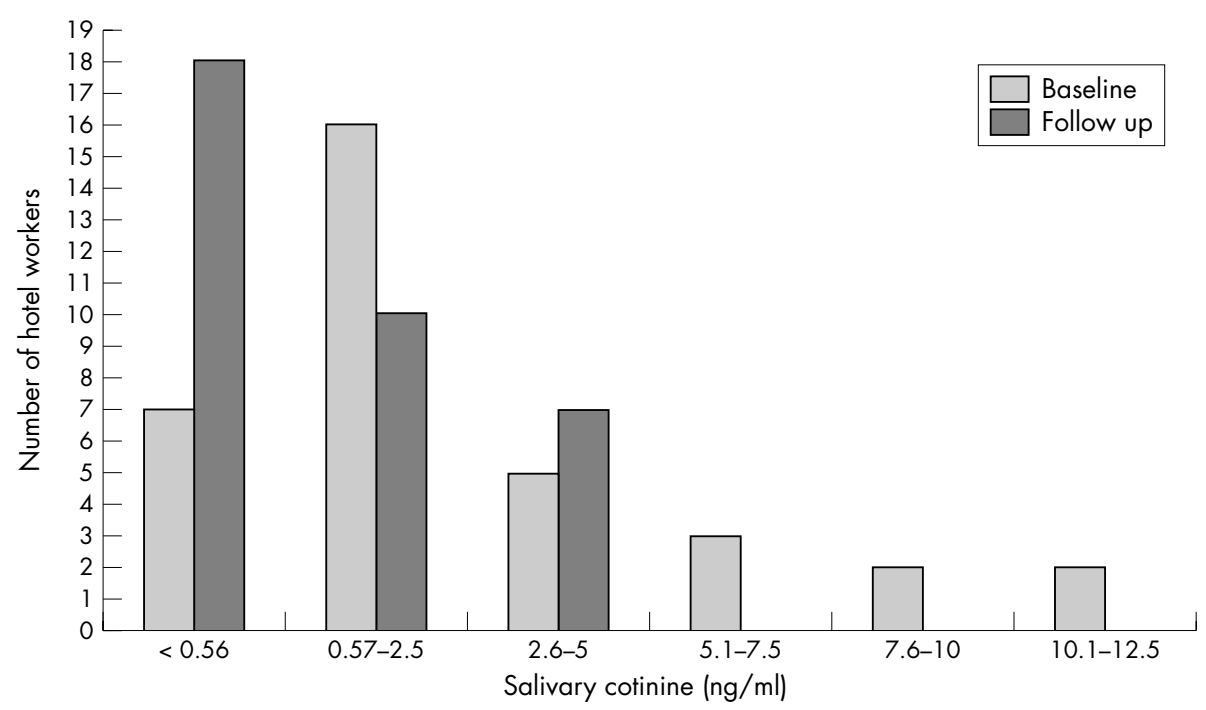

Figure 1 Salivary cotinine concentrations at baseline and follow up.

follow up this increased to $10(53 \%)$. Bars with designated outside smoking areas $(n=8)$ had higher concentrations of airborne nicotine at follow up than those that did not $(\mathrm{n}=11)\left(\right.$ mean $13 \mu \mathrm{g} / \mathrm{m}^{3}$, median $10 \mu \mathrm{g} / \mathrm{m}^{3} v$ mean $8.2 \mu \mathrm{g} /$ $\mathrm{m}^{3}$, median $\left.5.6 \mu \mathrm{g} / \mathrm{m}^{3} ; \mathrm{p}=0.31\right)$.

The mean number of smokers observed actively smoking indoors during four separate baseline visits to the venues ranged from 2.5-11.75; almost two thirds of bars (63\%) had 4-8 active smokers. At follow up no smokers were observed smoking indoors.

\section{DISCUSSION}

The study found that since the introduction of the national workplace smoking ban in Ireland, significant reductions in both air nicotine $(80 \%)$ and saliva cotinine concentrations (70\%) have been experienced. This corresponds with the reported compliance rates with the smoking ban exceeding $90 \%^{23}$ and should result in substantially lowered health impacts.

When compared to data available for England, median cotinine concentrations of Galway hotel workers fell to less than a sixth $(0.5 \vee 3.2 \mathrm{ng} / \mathrm{ml})$ of those found in London bar workers $^{15}$; however, much like other studies, exposure has not been totally eliminated ${ }^{11}{ }^{12}$ with Galway hotel workers' cotinine concentrations $25 \%$ higher than those found in all English non-smokers ${ }^{15}$ ( $0.5 \vee 0.4 \mathrm{ng} / \mathrm{ml}$ median) and more than twice those found in Galway school children from nonsmoking homes ${ }^{24}(0.6 \mathrm{ng} / \mathrm{ml} v 0.267 \mathrm{ng} / \mathrm{ml}$ geometric mean: SD $0.969 \mathrm{ng} / \mathrm{ml}$ ). This continuing exposure seems particularly the case for those undertaking bar work or waiting duties, whose work could involve them circulating in smoking areas or in areas in close proximity to where the migration of SHS into non-smoking areas from elsewhere may be a factor.
Biological markers are useful in quantifying exposure and an important step in linking exposure to relative risk of adverse outcomes. ${ }^{5}$ Whincup et $a^{25}$ related the 20 year cardiovascular mortality of 4729 randomly selected men in the UK to their serum cotinine at study entry. In the first four years of follow up, those with more cotinine had 3.7 times greater risk of coronary heart disease $(\mathrm{CHD})$ compared to those in the lowest quartile $(<0.7 \mathrm{ng} / \mathrm{ml})$, and the proportion with major CHD was comparable to that of light smokers. The proportion of Galway hotel workers exposed above this cut off point (saliva cotinine equivalent $0.56 \mathrm{ng} /$ $\mathrm{ml}^{26}$ ) declined from $80 \%$ (28) before the ban to $49 \%$ (17) after the ban. Although the Galway bar workers were selected to have little or no home exposure (usually a major contributor to cotinine), those in the upper half of exposure had higher cotinine concentrations, with a median $12 \%$ higher and 75 th centile $50 \%$ higher, respectively, than those in the Whincup et $a l^{25}$ study, which reported a significant dose-response trend.

Much of the recent data on the relationship of SHS and heart disease indicate the effect is acute, as well as chronic. Thus, healthy young non-smokers exposed to SHS for 30 minutes had compromised endothelium function comparable to that of smokers, activated platelets comparable to levels found in smokers, and increased presence of endothelial cell mortality in the blood ${ }^{27}$; for six hours after exposure, adverse impact on serum lipids were observed, including a significant decrease in the resistance of low density lipoprotein cholesterol (LDL-C) to oxidation and a significant increase in macrophage uptake of LDL-C. ${ }^{28}$ The recent experience of Helena, Montana, which had a $40 \%$ decrease in acute myocardial infarction after smoking was banned in workplaces and public places, ${ }^{29}$ demonstrates that short SHS exposures effects are not limited to cellular effects, but that SHS also affects the system as whole.

Table 2 Cotinine concentrations for hotel staff by type of work duties

\begin{tabular}{|c|c|c|c|c|c|c|c|c|c|c|}
\hline & \multicolumn{2}{|c|}{ Waiter ( $n=11$ ) } & \multicolumn{2}{|c|}{ Management $(n=10)$} & \multicolumn{2}{|c|}{ Other $(n=11)$} & \multicolumn{2}{|c|}{ Mixed $(n=3)$} & \multicolumn{2}{|c|}{ Total $(n=35)$} \\
\hline & Baseline & $F / U$ & Baseline & $F / U$ & Baseline & $F / U$ & Baseline & $F / U$ & Baseline & $F / U$ \\
\hline Mean & 4.59 & 1.46 & 1.19 & 1.24 & 2.6 & 1.1 & 2.88 & 1.43 & 2.86 & 1.29 \\
\hline SD & 4.24 & 0.88 & 1.67 & 1.13 & 3.0 & 1.68 & 3.36 & 2.06 & 3.36 & 1.29 \\
\hline Geometric mean & 2.5 & 0.98 & 0.48 & 0.65 & 1.3 & 0.36 & 0.87 & 0.51 & 1.17 & 0.6 \\
\hline Median & 3.9 & 1.6 & 0.55 & 0.95 & 3.1 & 1.7 & 2.0 & 0.4 & 1.6 & 0.5 \\
\hline 25th centile & 1.3 & 0.5 & 0.16 & 0.18 & 0.85 & 0.1 & 0.05 & 0.09 & 0.4 & 0.2 \\
\hline 75th centile & 9.5 & 2.2 & 1.6 & 2.2 & 2.6 & 2.6 & 6.6 & 3.8 & 4.2 & 2.2 \\
\hline
\end{tabular}

F/U, follow up. 


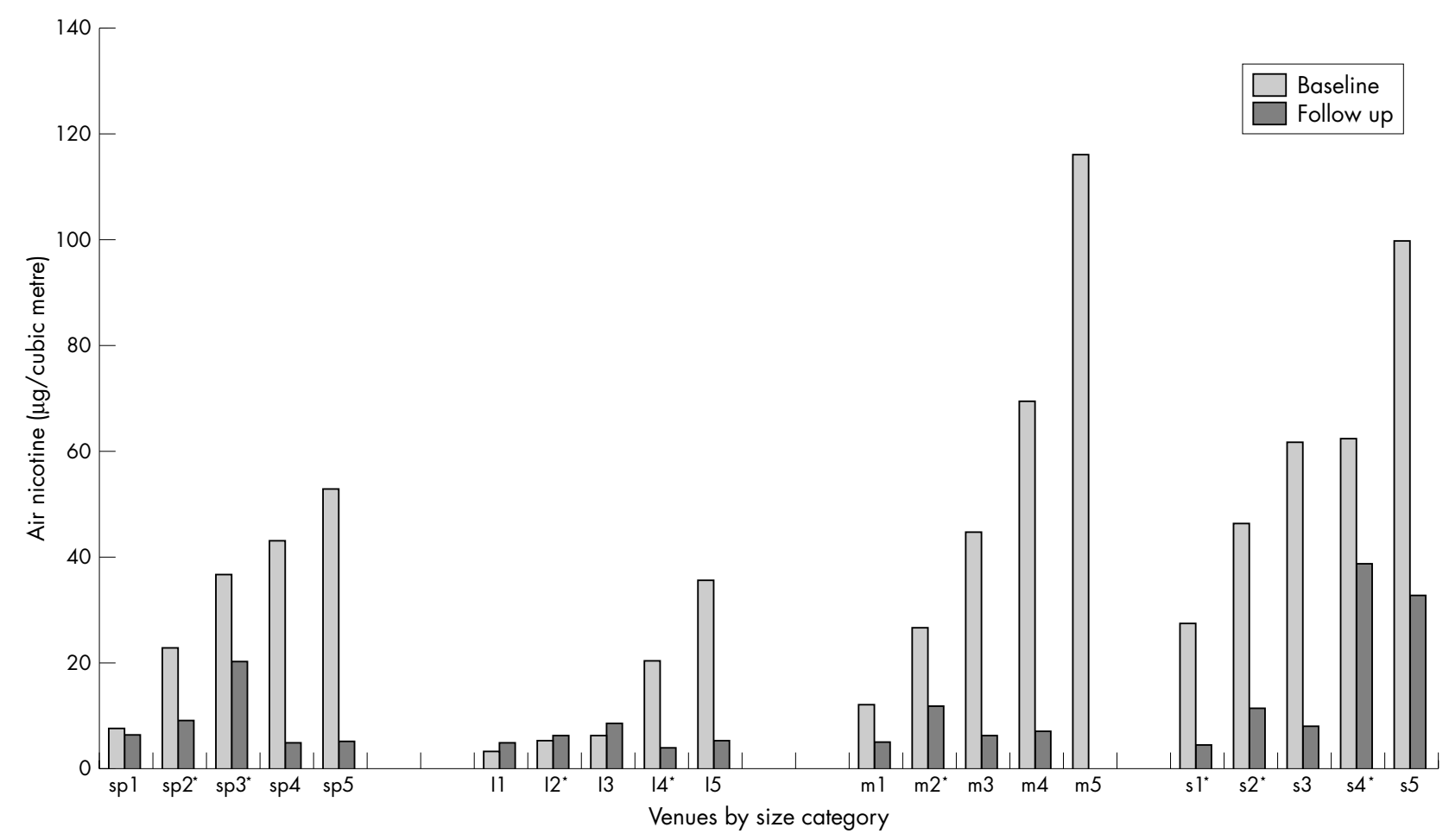

Figure 2 Airborne nicotine concentrations at bar venues (sp, super pub; l, large bar; m, medium bar; s, small bar; * denotes designated outdoor smoking area provided).

In addition, although any level of preventable exposure is unacceptable ${ }^{30}$ it can be useful to interpret measured air nicotine concentrations in terms of the population risk thresholds they may exceed. Repace et $a^{l^{11}}{ }^{32}$ estimated the point at which population risk decision thresholds would be exceeded for US regulatory authorities. They calculated that workplace environmental nicotine exposure of $2.0 \mu \mathrm{g} / \mathrm{m}^{3}$ for 45 years presented a lung cancer risk of three in 10000 , a de manifestis risk-that is, "a risk of obvious or evident concern" or risks so high that the US regulatory agencies have almost always acted to reduce them. All the bars in the Galway study exceeded this level both before and after the ban. However, the US Occupational Safety and Health Administration (OSHA), in evaluating urgently actionable risk to workers, uses a risk rate of one death per 1000 workers per $\mathrm{WLT}_{45}$, called the "significant risk of material impairment of health" level. It has been estimated that "significant risk" would occur at or above $6.8 \mu \mathrm{g} / \mathrm{m}^{3}$ for lung cancer and at $0.68 \mu \mathrm{g} / \mathrm{m}^{3}$ for heart disease. ${ }^{31} 32$ In Galway, median air nicotine concentrations fell from $35.52 \mu \mathrm{g} / \mathrm{m}^{3}$ to $5.95 \mu \mathrm{g} / \mathrm{m}^{3}$ and whereas three bars met the OSHA risk threshold at baseline, an additional seven bars complied at follow up resulting in 53\% (10) of bars falling below the "significant risk level for lung cancer only".

The implementation of the workplace smoking ban has been accompanied by a growth in café society, pavement cafes, and outdoor smoking shelters. The resultant new trend in smoking and its potential impact on outdoor and indoor exposures has received little consideration in the legislation. While a requirement for roofed outdoor smoking shelters is that not more than half of their perimeter is surrounded by one or more walls or similar structures, there is no legal requirement as to their minimum proximity to buildings nor is there a requirement as to the minimum proximity of smokers to open doors or windows. ${ }^{1}$ So that despite the dilution effect of outdoor air there is the potential for infiltration of tobacco smoke into indoor areas. Although there was an $83 \%$ reduction in air nicotine concentrations and median concentrations fell below $6.8 \mu \mathrm{g} / \mathrm{m}^{3}$, in those bars with designated outside smoking areas airborne nicotine concentrations were higher than in those bars without such an arrangement, suggesting that SHS may be migrating indoors. The extent to which outdoor smoke infiltration may be a contributor to indoor pollution and exposure levels in workers requires further investigation. Nevertheless, in the early weeks of the smoking ban significant reductions in exposure and associated risks have been observed. Based on an equation by Benowitz ${ }^{19}$ that relates airborne nicotine exposure to blood cotinine concentrations, we calculate that a 2-3 hour visit to a typical Galway pub would have exposed patrons to enough SHS with no other exposure to raise their cotinine above the referent level in Whincup et al. ${ }^{26}$ Before the smoking ban, three quarters of the pubs had measured levels of nicotine sufficient to produce this elevation, while after the ban fewer than $20 \%$ had such high levels of nicotine.

In recruiting hotel workers for the study, all staff who were on duty at the time the hotel was visited by a member of the study team were asked to participate. It must be acknowledged that this convenience sampling approach combined with the small sample size cannot ensure that the results are statistically representative of hotel workers in Galway city. This would have required a random sample of all hotel workers employed which was outside the time and cost constraints of the current study. In addition, by selecting only hotels for inclusion in the study, the sample is not representative of all hospitality establishments. This places limitations on the study in terms of its ability to make generalisations about the findings for the hospitality industry in Galway and indeed for Ireland as a whole. Because visits to obtain samples were unannounced and the shift patterns of the volunteers varied it was not possible to standardise the time into a shift that samples were obtained. At follow up our subjects were tested an hour and a half earlier into their shift than at baseline (mean 4.95 hours $v 6.6$ hours) equating to 


\section{What this paper adds}

For those advocating for smoking bans there are few studies that show the scale of exposure and risk reduction that may result from such bans. We used the unique opportunity of the Irish smoking ban to investigate its impact on hospitality workers.

During the first six weeks of the smoking ban's implementation the signs in terms of reduced exposure and risk are positive. However, the study suggests that despite high compliance rates with the ban, exposure to secondhand smoke is still possible for those working in exempted areas and those working where smoke may migrate from outdoor areas. Further research is required to assess the true extent and magnitude of these exposures.

roughly a $25 \%$ shorter shift. This may in part have contributed to the overall $70 \%(1.1 \mathrm{ng} / \mathrm{ml})$ reduction found but this contribution is felt to be small. For example, 90 minutes exposure at $17 \mu \mathrm{g} / \mathrm{m}^{3}$ (the median for the smokiest of restaurants in a recent European study ${ }^{9}$ ) would account for an elevation in saliva cotinine of approximately $0.32 \mathrm{ng} / \mathrm{ml} .^{19}$

Although the scale of reduction found in both these popular markers of SHS exposure are on a par with studies that have examined smoking bans or non-smoking policies $^{671112}$ the difficulty remains as to how we interpret such data in terms of relative exposure and risk for normal daily exposures to SHS. This is so, partly because of the paucity of data on population SHS exposure patterns and partly because so little is still known of the precise dose-response relationship that SHS has with cardiovascular disease. As existing smoking bans have yet to result in the total elimination of community based exposures, these remain important research issues for public health.

\section{ACKNOWLEDGEMENTS}

The authors are grateful to Associate Professor James Hyde who gave advice on the study design, Dr Declan McKeown who advised on ethical approval and informed consent, Eleanor Burke, and Marian Brett who assisted with fieldwork. We are also grateful to Professor Martin Jarvis who assisted in the analysis and interpretation of the data, and to Donna Dobinson (ABS), Maria Jose Lopez, and Manel Nebot (Public Health Agency, Barcelona) for their advice, assistance, and analysis of samples. Finally, we are indebted to Priya Prendergast and our colleagues in the Health Service Executive, Western Area for their generous support and assistance throughout this project. The research was supported by funding from Health Service Executive Western Area, Irish Cancer Society, and Irish Heart Foundation. For JL Repace, funding was provided by the Flight Attendant Medical Research Institute Distinguished Professor Award.

\section{Authors' affiliations}

M Mulcahy, Health Service Executive, Western Area, The Annex, Galway, Republic of Ireland

D S Evans, Health Service Executive, Western Area, Department of Public Health, Merlin Park Hospital, Galway, Republic of Ireland S K Hammond, University of California, School of Public Health, Berkeley, California, USA

J L Repace, Tufts University School of Medicine, c/o Repace Associates, Inc, Bowie, Maryland, USA

M Byrne, Department of Experimental Physics at National University of Ireland, Galway, Republic of Ireland

Competing interests: MM is a member of the Board of ASH Ireland. JLR is also a secondhand smoke consultant.

Statement of independence: The research was conducted independently and without input or influence by the funding organisations

Ethical approval was not necessary

\section{REFERENCES}

1 Office of Tobacco Control, Ireland. National Law. http://www.otc.ie/ legislation.asp (Accessed 19 Jan 2004).

2 Allwright S, McLaughlin P, Murphy D, et al. A report on the health effects of environmental tobacco smoke (ETS) in the workplace, Health and Safety Authority, Office of Tobacco Control, Ireland 2002. http://www.otc.ie/ article. asp? article = 29(Accessed 25 Jan 2005)

3 UK Department of Health: Scientific Committee on Tobacco and Health (SCOTH). Second-hand Smoke: Review of evidence since 1998. Department of Health, London: DH Publications, November, 2004.

4 World Health Organization International Agency for Research on Cancer. Tobacco smoke and involuntary smoking. Monograph on the Evaluation of Carcinogenic Risks to Humans. Lyon: WHO IARC, 2004; 83.

5 California Environmental Protection Agency. Proposed identification of environmental tobacco smoke as a toxic air contaminant, CEPA, October, 2004.

6 Hedley AJ, McGhee SM, Repace J, et al. Passive smoking and in non-smoking catering workers in Hong Kong. The combined risks for heart disease and cancer. COSH Hong Kong Council on Smoking and Health 2001 Report No.8. 2001.

7 Hammond SK, Sorensen G, Youngstrom R, et al. Occupational exposure to environmental tobacco smoke. JAMA 1995;274:956-60

8 Cains T, Cannata S, Poulos R, et al. Designated "no-smoking" areas provide from partial to no protection from environmental tobacco smoke. Tobacco Control 2004;13:17-22

9 Nebot M, Lopez MJ, Gorini G, et al. Environmental tobacco smoke exposure in a sample of European cities project. Tobacco Control 2005;14:60-3.

10 Jarvis MJ, Foulds J, Feyerband C. Exposure to passive smoking among bar staff. Br J Addiction 1992;87:111-13.

11 Dimich-Ward H, Gee H, Brauer M, et al. Analysis of nicotine and cotinine in hair of hospitality workers exposed to environmental tobacco smoke. J Occup Environ Med 1997;39:946-8.

12 Al-Delaimy W, Fraser T, Woodward A. Nicotine in hair of bar and restaurant workers. NZ Med J 2001;114:80-3.

13 Siegel M, Skeer M. Exposure to second hand smoke and excess lung cancer mortality risk among workers in the $\mathrm{B}^{\prime} \mathrm{s}$ : bars, bowling alleys, billiard halls, betting establishments and bingo parlours. Tobacco Control 2003;12:333-8.

14 Mulcahy M, Repace J. Passive smoking exposure and risk for Irish bar workers. Proceedings of Indoor Air 2002. Monterey, California. http:// www.indoorair2002.org/Proceedings_order.pdf.

15 Jarvis M. Quantitative survey of exposure to other peoples smoke in London for staff. London: Department of Epidemiology and Public Health, University College London, 2001.

16 Repace JL. Respirable particles and carcinogens in the air of Delaware hospitality venues before and after a smoking ban. J Occup Environ Med 2004;46:887-905

17 Eisner M, Smith A, Blanc P. Bartenders' respiratory health after establishment of smoke-free bars and taverns. JAMA 1998;280:1909-14.

18 Ott W, Switzer P, Robinson J. Particle concentrations inside a tavern before and after prohibition of smoking: evaluating the performance of an indoor quality model". J Air Waste Management Assoc 1996;46:1 120-34.

19 Benowitz NL. Biomarkers of environmental tobacco smoke exposure. Environ Health Perspect 1999;107(supp 2):349-55.

20 Feyerabend C, Russell MAH. A rapid gas-liquid chromatographic method for the determination of cotinine and nicotine in biological fluids. J Pharm Pharmacol 1990;42:450-2.

21 Hammond SK, Leaderer BP. A diffusion monitor to measure exposure to passive smoking. Environ Sci Technol 1987;21:494-7.

22 Jarvis MJ, Goddard E, Higgins V, et al. Children's exposure to passive smoking in England since the 1980s: cotinine evidence from population surveys. BMJ 2000;321:343-5

23 Office of Tobacco Control Ireland. Report confirms continuing high levels of compliance with smoke-free workplace legislation. Press release http:// www.otc.ie/article.asp?article = 253 (Accessed 24 Jan 2005).

24 Mulcahy M, Evans D. How smoke free is Ireland? Evidence of passive smoking in children. Proceedings of 12 th World Conference on Tobacco or Health, 2003; Abstracts, 434-5.

25 Whincup PH, Gilg JA, Emberson JR, et al. Passive smoking and risk of coronary heart disease and stroke: prospective study with cotinine measurement. BMJ 2004;329:200-5.

26 Jarvis $M$, Primatesta $P$, Erens $B$, et al. Measuring nicotine intake in population surveys; comparability of saliva cotinine and plasma cotinine estimates. Nicotine Tob Res 2003;5:349-55.

27 Glantz S, Parmley W. Even a little secondhand smoke is dangerous. JAMA 2001;286:462-3

28 Valkonen M, Kuusi T. Passive smoking induces atherogenic changes in lowdensity lipoprotein. Circulation 1998;97:2012-16.

29 Sargent RP, Shephard RM, Glantz SA. Reduced incidence of admissions for myocardial infection associated with public smoking ban: before and after study. BMJ 2004;328:977-80.

30 World Health Organization. Environmental tobacco smoke. Chapter 8.1. WHO Air Quality Guidelines for Europe 2000. Geneva: WHO.

31 Repace J, Lowrey A. An enforceable indoor air quality standard for environmental tobacco smoke in the workplace. Risk Analysis 1993;13:463-75.

32 Repace J, Jinot J, Bayard S, et al. Air nicotine and saliva cotinine as indicators of workplace passive smoking exposure and risk. Risk Analysis 1998;18:71-83. 